\title{
Computer science in Dutch secondary education: independent or integrated?
}

\author{
Pieter C. van der Sijde and B. Gerard Doornekamp \\ Untversity of Twente, Postbus 217, 7500 AE Enschede, Netherlands
}

\begin{abstract}
Van der Sijde, P.C. and B.G. Doornekamp, Computer science in Dutch secondary education: independent or integrated?, Education \& Computing 8 (1992) 217-223.

Nowadays, in Dutch secondary education, computer science is integrated within school subjects. About ten years ago computer science was considered an independent subject, but in the mid-1980s this idea changed. In our study we investigated whether the objectives of teaching computer science as an independent subject are met when computer science is integrated within school subjects. The main problem was that there was no formal curriculum of computer science as an independent subject. Therefore we interviewed 13 experts in the field of computer science and then compared this formal curriculum with the operational (integrated) curriculum, which is still in the development stage. It appears that most of the components of the formal curriculum are being covered by the operational curriculum, and we therefore concluded that these curricula are equivalent, although there may be differences in the level of teaching. In our opinion the best approach to computer science is to combine the independent and the integrated approaches.
\end{abstract}

Keywords: computer science; secondary education; curriculum research.

The title of this article is, in a sense, misleading. It has already been decided that computer science in Dutch secondary education will be integrated within other school subjects, such as mathematics, economics and physics. On the other hand, the title does reflect the nature of the study we performed. The choice for the integration of computer science within other school subjects was a political, not an educational one. Computer science is an important subject and it will continue to be so in the future. Is the choice that was made a good one, or are there objections to it from an educational point of view, that is, with respect to the objectives for computer science instruction? Or, to rephrase this into our research question: what should be the objectives of computer science as a subject that will be examined at a nationwide level, and does the integration model meet these objectives?

In this article, we shall begin by describing part of the Dutch educational system, in order to clarify the context of our study, as well as describ- ing developments in computer science in the Netherlands. We shall then go on to describe our research.

\section{The context}

\section{The Dutch educational system}

We have no intention of describing the Dutch educational system in detail here, (see [3] for such a description). However, a brief outline will be useful. The formal educational system consists of three levels: primary (including kindergarten), secondary and higher education; we shall focus here on secondary education. Secondary education was fully restructured in 1968, and since then has comprised four types of education: pre-university (length six years; student's age ranging from 12 to 18 ), senior secondary (length five years; ages ranging from 12 to 17), junior secondary (length four years; ages ranging from 12 
to 16), and secondary vocational education. We restrict ourselves to pre-university education and senior secondary education.

It is usual to divide both pre-university education (PUE) and senior secondary education (SSE) into two levels: the fundamental level (PUE: Grades 8-11; sSE: Grades 8-10) and the top level (PUE: Grades 12 and 13; sSE: Grades 11 and 12). The study on which we report in this article deals with computer science in the top levels of PUE and SSE.

\section{Some developments in computer science in the Netherlands}

There have been many developments in computer science since the beginning of the $1980 \mathrm{~s}$. Schools have bought computers and put them into the classroom, while teachers have taught themselves what they thought they ought to know about computers, and taught this to students. It all started out as the teaching of programming: first, BASIC was thought to be suitable, then PAsCAL became fashionable, and then Comal was regarded as a language of great educational value. Banks and computer firms donated computers to schools. The Dutch government funded a number of studies and experiments (for example, the Computer Science Stimulation Action).

"Computer literacy" was a novel topic. What does it mean to be computer-literate? Do you need a computer to teach this topic to students? When should you start teaching it? Recently, a further new topic has entered the discussion: basic education for all students, to take place at the fundamental level of secondary education. How does computer science fit into this new framework? It was decided that "information science" would be introduced as a subject in the new basic education framework.

In January 1988, the Department of Education appointed a committee to advise the government on the objectives of the basic education framework of secondary education for information science. Information science is different from computer science. Information science contains elements of computer science, when it concerns operational and functional topics. But it is also about "information", i.e., knowledge and skills in the area of information sampling, organization and processing. In general, information science is about skills for which the computer is an important instrument. The committee formulated the general objective for this subject as follows:

Information science education should aim at the understanding of processes of goal-directed information sampling, information processing, and information giving; in addition, education should be directed towards the enhancement of insightful use of information processing systems in situations in which they are possible, useful, and/or necessary, and to evaluate societal use of them. $[1$, p. 21]

This general objective is split into four sub-objectives:

(1) students should have insight into the processes of goal-directed information sampling, processing and giving, allowing them to deal with information and data;

(2) students should have a functional image of information processing systems, and should use such systems on the basis of this image;

(3) students should have some knowledge of the applications of information processing systems;

(4) students should have some insight into the societal implications of the use of information processing systems.

So far, these objectives for information science in the basic education component of secondary education are still no more than a proposal to the government; nevertheless, many schools are experimenting with this approach to information science (and computer science) at the fundamental level of secondary education.

\section{Our research}

Our research institute was confronted with a rather unusual question. Although the choice of the integrated approach to the implementation of computer science at the top level of sSE and PUE had already been made, we were asked to construct an outline of what computer science would be like if it were to be tested as an independent school subject. This question needs some clarification. As part of the aforementioned Computer Science Stimulation Action of the government, an experiment at the top level of secondary education started as part of the NIvo (New Information Technology in Secondary Education) project. When this project first started, there was a general feeling that computer science ought to be an 
independent school subject. The government even put such ideas into a policy statement to parliament in 1982. In 1986, however, an additional policy statement was formulated, in which the integrated implementation approach was put forward. The members of the Steering Committee of this particular part of the NIvo project were originally appointed to work along the lines of the ideas put forward in 1982; however, since these ideas changed in 1986, the task of the Steering Committee also had to change. In the Steering Committee, a concern emerged which can be expressed as follows: "What objectives shall we fail to achieve when we integrate computer science in existing school subjects, rather than teach computer science as an independent school subject?" This concern was the starting point for our research. To formulate the question in terms of the curriculum [2]: what is the difference between the formal curriculum (the independent curriculum the Steering Committee had in mind) and the operational curriculum (the curriculum actually being carried out: computer science integrated into other school subjects)? We shall first describe the formal curriculum, and afterwards the operational (integrated) curriculum.

\section{The formal curriculum}

A formal curriculum is, according to Goodlad et al. [2], the ideal curriculum transposed and elaborated into concrete guidelines and products. The ideal curriculum consists of the ideas, wishes and ideals embracing the curriculum. In order to come to terms with the formal curriculum, one should develop the concrete guidelines and products for a particular curriculum relating to toplevel computer/information science. That is just what we did. We made an inventory of the ideas and wishes of a group of people in the area of computer science, in order to develop the components of an ideal computer science curriculum for senior secondary students in the Netherlands.

Crucial to this approach is the selection of the group of people to interview to establish the components. We interviewed 14 experts in the area of computer science, from a variety of areas: three experts working in a university department of computer science, four working at a teacher training college and involved in computer science, three working in a company in the field of com- puter science, and four teachers working at the senior secondary level. To each of these experts, the same question was put: What do you think should be the objectives of a school subject, "computer science", at this moment? Although we did not restrict the experts in any way, we explicitly asked for their opinion on the following subjects: simulation, modelling, statistical data processing, databases, query languages and "systems thinking". We shall give a summary of our interviews in the form of components of computer science, and summarize them under different headings. Only topics or objectives mentioned by at least two experts are included.

\section{General objectives}

Computer science should strive for objectives that are "timeless". Computer science is a particular way of thinking; it is conceptual in nature; one has to make abstractions. The computer itself is merely a tool.

\section{Theoretical computer science}

Students should learn about predicate and proposition logic. They should gain a working knowledge of systems, artificial intelligence and expert systems. They must learn about the flow of information and the analysis of information. Students must know what algorithms, problem analysis and problem solving (top-down, bottom-up) strategies are. They must have knowledge of some basic concepts (for example, bit, byte) and of formal techniques.

\section{Hardware}

Students must have an elementary knowledge of computer architecture (including input media and peripherals), datacommunication, networks and basic concepts (semiconductor, (co)processor).

\section{Software}

Students should master the concepts behind software packages and shells (how they are built up and the logic within a package). They should learn to use operating systems, editors, graphics, databases, spreadsheets and simple applications of $\mathrm{CAD}$ / CAM and robotics.

\section{Programming}

The experts were divided on this point: some were in favour of teaching programming to the 
students in a computer language (BASIC, Pascal, Logo, Prolog, Ecol, Elan, C, and Lisp were mentioned by them). Others emphasized the importance of general knowledge of basic structures in languages (recursion, iteration, etc.); others still were opponents of teaching programming at all.

\section{Societal implications}

Students must become aware of the information systems in their direct environments (teleshopping, videotex). They should learn through concrete examples how computer science changed society. Students should know about jobs and opportunities in the area of computer science, and about its history.

\section{Statistical data processing}

Statistical data processing is not a part of computer science. It relates to it when it concerns the concepts and principles behind data processing, but, as such, it may be part of software.

\section{Simulation and modelling}

Students must learn to work with simulations in the framework of modelling.

\section{Databases (modelling, query)}

Students must learn to structure data. They should know how to deal with database packages. They must know how to manipulate data, using a query language (for example, SQL). Students should know the implications of databases for society (protection, privacy).

\section{Thinking in systems}

"Systems thinking" had several connotations for the experts: for systems theory to information systems. Each of these topics has been mentioned earlier.

\section{The operational curriculum}

As a result of the additional policy statement in 1986, a number of studies were undertaken to establish how computer science could be integrated into school subjects. During the years of the project, feasibility studies were performed for physics, mathematics (two studies), economics (two studies), social and political science, Dutch (first language), biology and history; the studies concerned the so-called "middle level" of sec- ondary education. We shall describe briefly the developments in these subjects when the studies were continued after the feasibility studies relating to curriculum and courseware development projects. Our description is based on publications of each of the projects, and upon interviews with one of the team members from each project.

\section{The middle level project}

The middle level is between the fundamental level and the top level, consisting of Grades 10 and 11 of both sSE and PUE. This project was carried out by researchers from the University of Utrecht, in cooperation with an educational research institute (sco, Amsterdam). Computer science was seen, ideally, as the completion of information science studies at the fundamental level (basic education), and as a preparation for computer science integrated in school subjects, leading to a nationwide examination. An experimental programme was designed for students in Grade 11, containing the following topics: operating systems, text processing, processing of information and relations between databases, design of a database, simple dynamic simulations and programming. The first phase of this project was completed at the end of 1988, and the project continued in 1989.

\section{Mathematics: automatic data processing}

At the end of 1987, the University of Groningen completed a feasibility study which was to lead to a proposal for the development of a programme and courseware for statistics and graphical processing of data. The programme and the courseware are now being tested, in order to establish whether the objectives are being met. The objectives for these particular subjects are that the students must learn how to handle a statistical problem and solve it using a computer and applications software, analyze a statistical problem, operate with a structured database, program in macros in a top-down manner and handle standard statistical packages (for example, sPss). The students must also learn about the range of application of various software packages.

\section{Social and political science}

Social and political science has, as its general objective, that students should gain knowledge, insight and skills in the area of social and politi- 
cal phenomena and issues. Computer science is part (at this moment) of the theme "technology and society". In general, the objective of computer science within this subject is to develop knowledge, insight and skills in the area of information theory and the functional aspects of systems development. This project is being carried out at the Institute for Curriculum Development.

\section{Business economics}

The project on business economics is being carried out at the University of Limburg. In this project, a course with five modules has been designed, to teach the following:

- how information works in organizations;

- what it is to control a database effectively;

- what systems are, and how to control a system;

- the history and prospects of automatization and the automatization department in business;

- how to solve business-oriented economic problems using a computer.

\section{Mathematics: dynamic simulation}

Dynamic simulation is a simulation method which emphasizes the structure and behaviour of systems with more than one feedback loop. Dynamic simulation is important to computer science because of its contribution to modelling. In the course material, attention is given to how to handle a package for dynamic simulation, and how to build and use models to solve problems. This project is being carried out at the Free University of Amsterdam.

\section{Physics}

The project to incorporate computer science in physics was started in 1986 at the University of Amsterdam and resulted in a programme (and courseware) for physical science. Within this programme, two series of lessons are developed. The first is on production automatization, the second on computer applications in physics. In these series of lessons, the following topics are addressed:

Table 1

Overview of topics and components of computer science (as an independent subject) elaborated in the integrated approach

Topics and components in computer science as Topics and components an independent subject

General

Theoretical computer science

Hardware

Software

Programming

Societal implications

Statistical data processing (not in the components identified by the experts) Simulation and modelling

Databases (modelling, query)

Thinking in systems

a DM: dynamic modelling

b SDP: statistical data processing integrated in projects

All projects

All projects

Physics

Mathematics: $\mathrm{DM}^{\mathrm{a}}$

Mathematics: SDP b

Middle level

Only in application languages:

Mathematics: DM

Mathematics: SDP

Middle level

Social and political science

Business economics

Middle level

Mathematics: SDP

Middle level

Mathematics: DM

Mathematics: SDP

Business economics

Middle level

Mathematics: DM

Physics 
- what measurement and control mean, what these concepts mean in computer science and how they can be applied using a computer;

- the functions and properties of sensors, processors and actuators;

- how to use a computer in modern scientific research.

\section{Comparison of the formal and operational curric- ula}

It is difficult to compare the formal (independent) and the operational (integrated) curricula, as the formal curriculum has not been implemented, and the operational curriculum is still in the stage of development, and thus is only operational in experimental settings. From the comparison shown in Table 1, it appears that most aspects of the formal curriculum are also part of the operational curriculum. However, there are some striking differences. For example, in the formal curriculum, there is no place for statistical data processing, while in the operational curriculum, this is part of the mathematics integration. Another interesting aspect is programming. The experts we interviewed in order to construct the formal curriculum were divided; some were in favour, others were against it. In the operational curriculum, there is an emphasis on applied programming, meaning programming in application languages, such as query languages or macros. Some aspects receive attention in just one subject area. Physics is the only subject area that involves any attention to hardware.

As Table 1 shows, most of the aspects and topics of the suggested components for an independent course (the formal curriculum) are being covered by the projects which are piloting the integrated approach (the operational curriculum). Based on this comparison, we could be tempted to conclude that the integrated approach is equivalent to the approach of making computer science an independent school subject. Before we draw such a conclusion, however, we should point out that we only compared the aspects and the topics, and not the level on which each of the topics is, or would be, taught. There might be a wide discrepancy between the level of teaching the experts had in mind and what is, or would be done, in the integrated approach. Bearing this criticism in mind, we can conclude that there is a fair resemblance between the formal curriculum and the operational curriculum.

\section{Discussion}

The Dutch approach to computer science, whereby it is integrated into existing school subjects, is, in our opinion, a good approach; it appears from our study that there is a fair resemblance between what computer science education should be, in the eyes of a number of experts, and what is actually being realized in the integrated computer science projects initiated by NIVO. The integrated approach is apparently equivalent to the independent approach, but the question remains as to which approach to computer science education will be the best in the long run.

We think that the best approach to the teaching of computer science will be a combination of the independent and the integrated approach. Computer science should be integrated in all possible school subjects and on the basis of this experience, criteria for nationwide examinations should be developed. Through this approach, most of the students will be involved in computer science, or, at least, will gain some basic knowledge and skills. But computer science should also be a school subject in its own right. In studying this subject, students will not only be prepared for further education, but will also learn more systematically about computer science. In the Netherlands, this would mean that the information science course of the basic education would be continued at the top levels of SSE and PUE, as computer science (an independent school subject), as well as being integrated in established school subjects. This dual approach to computer science has several implications. The first is that, for many school subjects curriculum materials must be developed to implement computer science as part of each subject. Second, a computer science curriculum must be developed for both SSE and PUE. A third implication concerns teachers and teacher training. In the Netherlands, we have no officially recognized computer science teachers, nor do we have teachers' trainers to instruct present and future teacers on how to integrate computer science in school subjects. The NIvo project (and its successor) were pioneers in this area, but only for the subject areas described in 
this paper. This means a lot of time and effort must go into the development of curriculum materials and courseware and, most of all, into training the teacher trainers. We think that the first steps on a long road have been taken in the Netherlands.

\section{References}

[1] Development Group Information Science, Eindtermen voor het vak informatiekunde (Objectives for the subject of information science) (SDU, The Hague, 1989).

[2] J.I. Goodlad and Associates, Curriculum Inquiry: the Study of Curriculum Practice (McGraw-Hill, New York, 1979).

[3] W. Nijhof and J. Streumer, Netherlands. In: T.N. Postlethwaite, ed. The Encyclopedia of Comparative Education and National Systems of Education (Pergamon, Oxford, 1988) 498-506

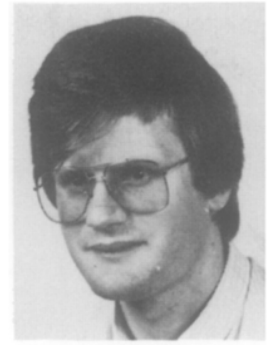

Pieter C. van der Sijde is a researcher at the Centre for Applied Research in Education of the University of Twente (Netherlands). He studied psychology at the Free University of Amsterdam and received his PhD at the University of Twente. He is involved in a wide variety of studies in the area of information technology in education.

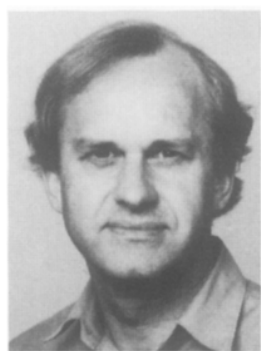

B. Gerard Doornekamp works as a researcher at the Centre for Applied Research in Education of the University of Twente (Netherlands). $\mathrm{He}$ studied at the University of Utrecht, and started his career at the Department of Education of the University of Twente. He has done several assessment studies on technology education in primary and secondary education and the position of teacher training for primary schools in institutes of higher education. At the moment he is taking part in a pilot study on computer integration in secondary education. 